Orlando Valverde, geógrafo e historiógrafo. Fez curso de aperfeiçoamento em geografia na

Universidade de Wisconsin (EUA); ex-professor nas universidades da Califórnia - UCLA,

Heidelberg (Alemanha Ocidental), Bordeaux

(França) e PUC/RJ, atualmente é presidente da

Campanha Nacional de Defesa e pelo

Desenvolvimento da Amazônia - CNDDA.

\title{
Ocupação da Amazônia e defesa florestal
}

\section{O que é e o que representa a hiléia}

Dos três grandes domínios de selvas equatoriais da Terra, o da América tropical é o maior deles. Estende-se de norte a sul, desde a costa oriental do México até o centro da Bolívia, e de leste a oeste, desde São Luís do Maranhão até altitudes médias das vertentes orientais dos Andes.

A hiléia representa mais de $20 \%$ da biomassa existente no planeta, embora a taigá ${ }^{1}$ siberiana cubra uma superfície bem maior; enquanto esta encerra $250 \mathrm{~m}^{3} / \mathrm{h}$ a de biomassa, a hiléia alcança, em média, $750 \mathrm{~m}^{3} / \mathrm{h}$. Pode-se afirmar, grosso modo, que um terço das árvores da Terra inteira está na floresta equatorial da América.

Mais de 250 espécies arbóreas da Amazônia brasileira já são conhecidas como fornecedoras de madeiras nobres, potencialmente comerciáveis. Apesar de figurar este item em primeiro lugar na pauta das exportações atuais do Estado do Pará, somente onze espécies botânicas de madeiras foram exportadas, em 1981, por este Estado.

A despeito de que a maior parte dos recursos aproveitáveis da Floresta Amazônica seja ainda ignorada, já se conhece imensa variedade de produtos que dela se poderão obter, com o nível atual da tecnologia. Por exemplo:

- madeiras de marcenaria: como o mogno, ucuuba, cedro, maçaranduba, freijó, diversos louros, quaruba, etc,;
- celulose e papel: além das árvores específicas para a produção de celulose de fibra longa, podese hoje fabricar bom papel com as espécies heterogêneas contidas em um hectare qualquer da mata equatorial;

- combustíveis: lenha e carvão vegetal já são tradicionalmente explorados; mas a produção de etanol tornou-se economicamente viável com os altos preços dos derivados de petróleo;

- óleos essenciais: o pau-rosa (Aniba roseodora ou A. duckeil é uma árvore em via de extinção, por causa de sua extração depredatória, na faixa entre Santarém e Manacapuru. O desperdício na produção de sua essência é muito grande, visto que as foIhas nunca foram aproveitadas, como poderia ser feito, de acordo com trabalho publicado pelo Instituto Nacional de Pesquisa da Amazônia - INPA. O cumaru (Coumaruna odorata) é muito conhecido pelas indústrias de perfumes e química-farmacêutica. As perspectivas para a implantação de fábricas de perfumes são enormes, dependendo apenas de conhecimento da flora e de tecnologia. O que lá existe, até agora, são pequenas indústrias quase artesanais;

- produtos farmacêuticos: várias plantas medicinais amazônicas são tradicionalmente conhecidas, como a ipecacuanha ou poaia (Cephelis ipecacuanha), ora em via de extinção, e a salsaparrilha; pouco se sabe, entretanto, sobre a maioria das plantas da hiléia. Os grandes conhecedores dessa flora são os índios; mas, como bem afirmou o dr. Ghillean 
Prance, vice-diretor do Jardim Botânico de Nova York, tudo indica que eles desaparecerão antes da floresta2;

- alimentos: incrível variedade de alimentos pode ser obtida de diferentes partes dos vegetais da selva. Apenas sobre frutos comestíveis da Amazônia, o Museu Paraense Emílio Goeldi - MPEG, editou uma publicação especial, que se encontra em seu terceiro volume. A raiz da mandioca, o estipe de palmeiras, como o do açaí (Euterpe oleracea), explorado comercialmente, e o do babaçu (Orbygnya sp.). A folha do jambu (Wulffia Stenoglossa) é usada no preparo do tacacá, prato regional. As folhas de duas amarantáceas, utilizadas pelos caboclos do Amazonas, analisadas por técnicos do INPA, revelaram qualidades nutritivas superiores às da alface e da couve;

- látices: o látex da seringueira (Hevea brasiliensis) e de outras árvores produtoras de borracha, dos gêneros Hevea e Castilloa, como o caucho, geraram o surto de povoamento da Amazônia, do fim do século passado e início deste, com prosperidade notável em Belém e Manaus. Gomas nãoelásticas, como látex da sorva (Couma spp.), da balata (Mimusops bidentata), maçaranduba (Manilkara huberi) e outras árvores são exportadas, com destino à fabricação de chicletes;

- fibras, podem ser obtidas de cipós, palmeiras e outras plantas nativas;

- venenos, como o timbó e o curare.

- flores: a Amazônia é o maior repositório mundial de orquídeas. Mais de duas mil espécies e variedades dessa família são conhecidas, sendo algumas de alto valor comercial. Entretanto, somente uma nova e pequena sociedade de orquidófilos existe na Amazônia, situada em Manaus. O cultivo bemorientado poderia abrir novos horizontes para uma floricultura tropical.

Dentre todos esses recursos, releva em importância a energia, captada da irradiação solar, através da fotossíntese. A fonte primária de toda a energia na Terra é o Sol. Desde a Revolução Industrial, grande ênfase tem sido dada ao consumo de combustíveis fósseis - carvões e petróleo - , substâncias que acumularam a energia solar captada em outras eras geológicas e que, por isso mesmo, são formas não-renováveis de energia.

O álcool, em particular o etanol, pode ser obtido de plantas cultivadas - cana, mandioca, sorgo sacarífero, babaçu - , mas também diretamente da madeira, como foi apontado anteriormente. É uma forma de energia difusa, renovável, para a qual o Brasil já criou uma tecnologia de vanguarda, para seu aproveitamento. Essa energia depende da irradiação solar atual, sendo, por isso, especialmente abundante em regiões cujos recursos hídricos e temperaturas permitem o metabolismo vegetal durante o ano inteiro. Estas premissas colocam o Brasil em situação ímpar, visto que é o maior país tropical do mundo. Ele recebe maior quantidade de irradiação solar que qualquer outro e possui as maiores descargas fluviais. Nestas circunstâncias, preservar a hiléia amazônica representa assegurar o futuro do Brasil, nesta era de revolução energética, ora em início.

A hiléia brasileira reveste uma superfície de $3.972 .000 \mathrm{~km}^{2}$ (46,6\% da área do Brasil), localizada no norte de nosso país, abrangendo a maior parte dos estados do Amazonas, Pará, Acre, Mato Grosso, Rondônia; Territórios do Amapá e Roraima, bem como o oeste do Maranhão e o extremo norte de Goiás.

\section{Origem e manutenção}

Até o fim da era mesozóica ${ }^{3}$, no lugar onde existe agora a bacia sedimentar do Amazonas havia um golfo, que abria para o Oceano Pacífico. O soerguimento dos Andes, a partir daquela época, facilitou o entulhamento dessa região. Materiais arrancados pela erosão à citada cordilheira, bem como aos velhos planaltos brasileiro e guiano, durante o terciário, deram origem aos tabuleiros que hoje constituem a chamada "terra firme". Na transição do terciário para o quaternário, esses baixos platôs terciários foram aplainados, sob condições de clima mais seco do que o atual; mas o Rio Amazonas, mesmo com descarga muito menor do que tem hoje, foientão capaz de abrir caminho para o Atlântico.

Durante as glaciações quaternárias, especialmente na última (Würm), o nível dos oceanos esteve mais baixo que o atual cerca de 60 metros, em virtude da grande quantidade de suas águas estarem retidas nas calotas polares sob a forma de gelo. Em conseqüência, o Rio Amazonas e seus principais afluentes encaixaram profundamente seus leitos nos tenros sedimentos terciários e, por isso mesmo, o lençol d'água subterrâneo se aprofundou, e o revestimento vegetal predominante tornou-se, nesse período, de cerrados abertos (cujas árvores têm maior desenvolvimento radicular em profundidade que as das florestas). As chuvas eram mais concentradas que hoje, na Amazônia. A alternância com as estiagens permitia a formação de crostas lateríticas, e o forte escoamento superficial formou os horizontes de laterita pisolítica ${ }^{4}$.

A floresta equatorial se restringia a pequenos "refúgios" dispersos, situados, na maioria, no sopé oriental dos Andes. Três deles foram localizados no atual território brasileiro.

Quando as temperaturas de novo se tornaram mais altas, durante a transgressão flandriana ${ }^{5}$, o ní- 
vel dos oceanos se elevou. O Rio Amazonas e seus tributários provenientes dos Andes construíram suas várzeas, acumulando nas margens seus aluviões. Os outros afluentes, com cargas sólidas reduzidas, encharcaram as terras vizinhas, formando lagos e igapós.

A partir dos "refúgios", as matas se estenderam pelas margens dos rios, formando florestas de galerias; depois, subiram as vertentes e coalesceram no alto dos tabuleiros. Assim, como fato geográfi$\mathrm{co}$, a hiléia amazônica é geologicamente recente, posterior à última glaciação, isto é, com menos de dez mil anos de idade.

Um dos aspectos mais enganadores que a hiléia apresenta é sua pujança, mesmo sobre solos muito pobres. Os seus descobridores imaginaram que somente solos de grande fertilidade poderiam sustentar uma formação tão densa e verdejante.

O ecossistema da hiléia mantém uma formação-clímax ${ }^{6}$, auto-sustentada, independente da fertilidade do solo. As análises de águas realizadas por H. Sioli (1981/82) e sua equipe demonstraram que: a chuva que cai sobre a floresta é composta praticamente de água destilada, adicionada de anidrido carbônico $\left(\mathrm{CO}_{2}\right)$; a água que goteja das folhas e escorre pelos galhos e troncos das árvores tem um $\mathrm{pH}$ quase neutro, é rica em bases solúveis e húmus; a água proveniente das fontes do tabuleiro terciário é rica em ácido húmico, muito pobre em bases solúveis, tendo assim um $\mathrm{pH}$ de valor baixo.

Desses fatos se tira a seguinte explicação: os nutrientes recolhidos pela água da chuva na Floresta Amazônica provêm dos excrementos de sua riquíssima fauna arborícola - aves, macacos, insetos - , bem como dos restos de plantas e animais que ali viviam. Esse material é quase totalmente reciclado, seja através de microorganismos - fungos, cogumelos, algas, bactérias, etc. - , seja através da rede fina e pouco profunda do sistema radicular das árvores da hiléia. Raras são aquelas que possuem raiz pivotante. O raizame das árvores forma uma teia a pequena profundidade, ou se estende sobre o solo, como enormes serpentes. Umas árvores se escoram sobre sapopembas, raízes chatas, verticais, triangulares, como as sumaúmas (Ceiba pentandra); outras se erguem sobre um ensarilhado de raízes adventícias.

A reciclagem de nutrientes é tão intensa que um aspecto banal, dentro da mata, é ver-se um tronco caído coberto de "cogumelos de orelha", ou uma folha sobre o solo, ainda em decomposição, atacada por outro cogumelo, um micélio, por exemplo célula única, gigantesca, tendo um prolongamento que suga nutrientes hauridos da folha, e outro, que pode medir até um metro de comprimento, levando- os diretamente à raiz de uma árvore, de onde, por seu turno, recebe água e seiva para sua própria sobrevivência.

Aágua utilizada dessa forma no metabolismo das plantas retorna depois à atmosfera pela evapotranspiração. Dada a importância do "vento geral", que sopra constantemente de leste para oeste no Baixo Amazonas, a água da chuva é reciclada várias vezes sobre a região. E. Salati et alii (1978) comprovaram que cerca de $50 \%$ das chuvas caídas em Manaus provêm da evapotranspiração da hiléia que lhe fica a leste, e não da evaporação direta das águas do Atlântico. Daí se deduz como corolário que, a continuar a devastação acelerada na Amazônia do leste e central, as chuvas ficarão drasticamente reduzidas em Manaus e nos países vizinhos do oeste (Peru e Colômbia).

\section{Exploração das florestas equatoriais}

Até agora, toda a exploração direta da Floresta Amazônica tem sido feita de maneira seletiva, em busca de uma espécie ou gênero botânico, fornecedor de determinada mercadoria: Hevea para a borracha, Bertholletia excelsa para a castanha, madeiras finas como o mogno (Swietenia macrophyla). "A riqueza botânica da hiléia corresponde a uma pobreza econômica", afirmou P. Deffontaines (1945). De fato, a heterogeneidade da selva dificulta essa exploração seletiva. Ademais, na Amazônia, todos os grandes plantios de uma só espécie têm resultado em malogros comerciais, já verificados em Belterra, com seringueiras; em Tomé-Açu, com pimenta-do-reino; no Jari, com Gmelina arborea.

Nos trópicos úmidos do Velho Mundo, técnicos das potências metropolitanas conseguiram, no passado, alguns êxitos no aproveitamento racional dos solos e da floresta, cujos resultados foram depois anulados pelo odioso instituto colonialista que governava aqueles países.

Os agrônomos belgas haviam concluído, em suas pesquisas, que as lavouras consorciadas dos nativos rendiam mais, naquelas condições ecológicas, do que as mesmas culturas singelas, tratadas com as técnicas européias. Isto porque os solos dos trópicos úmidos não devem ficar desnudos, expostos às intempéries. Projetaram, assim, um sistema, vulgarmente conhecido como "de corredores", porque é organizado em faixas na direção leste-oeste, com 100 metros de largura, alternadas com iguais faixas de mata. Cada faixa era cultivada após derrubada e queimada, com plantios consorciados e sucessivos, de modo a manter o solo sempre ocupado durante quatro anos, com: milho (duas vezes), arroz, banana, mandioca (duas vezes) e amendoim (Galvão, M.C.C., 1956). 
Cada faixa é cultivada em conjunto, durante quatro anos consecutivos; depois é deixada em pousio durante dezessete anos, em capoeira enriquecida com leguminosas de crescimento rápido. Isto poderia ser feito na Amazônia com a imbaúba (Cecropia spp.) ou alguma leguminosa heliófila.

No aglomerado composto de vinte a quarenta pessoas, reunidas em habitat nucleado, de tipo linear, cada família recebia um pequeno lote de vinte áreas, com casa, cozinha e galinheiro. À frente, em lugar de jardim, plantavam-se frutas cítricas; atrás, fruteiras diversas. Mas, ao fundo de tudo, em faixas indivisas, seguem-se: o cafezal e o palmeiral de dendê (Elaeis guineensis).

Em terras planas, este sistema deu grande resultado, com bons excedentes de culturas comerciais, até que os belgas foram expulsos do país, em decorrência das lutas políticas e raciais.

Alguns melhoramentos foram ou poderiam ser introduzidos nesta estrutura: semeadura de leguminosas de cobertura, logo após cada quatro anos de cultivo, como o Calapogonium mucunoides, a Centrosema pubescens, etc; a adoção de um padrão poligonal de habitat rural, que aproximaria mais as habitações e deixaria, no fundo, área maior para as culturas permanentes (café e dendê); introdução de criação de gado leiteiro estabulado e de asininos...

De qualquer forma, áreas planas seriam facilmente selecionadas com imagens de radar, na faixa próxima aos eixos rodoviários. Os colonos que vão povoar a Amazônia falam todos a mesma língua, têm a-mesma nacionalidade e a mesma cultura. Estão num nível técnico-cultural francamente mais avançado que o dos congoleses. Os nordestinos, ademais, conservam muito acentuados os laços de família. Nessas condições, o sistema dos corredores, em suas linhas mestras, teria probabilidades muito maiores de êxito na Amazônia que no Zaire.

Sistema agrossilvicultural muito mais antigo, porém igualmente racional e engenhoso, foi aplicado pelo governo britânico, em suas colônias do sul da Ásia. Alarmado com a devastação feita pelos nativos na Birmânia, a serviço de empresas madeireiras em busca de pau-teca (Teciona grandis), e para suas roças - em birmanês taungya (pronuncia-se tânguia) de subsistência, não hesitou o governo de sua majestade em contratar para superintendente das florestas, naquela colônia, o silvicultor alemão Dietrich Brandis, em 1856. A partir daí, este se tornou o fundador da silvicultura tropical.

É surpreendente como, sendo a Inglaterra a pátria do capitalismo e do colonialismo moderno, já em 1862, o governador-geral das Indias não teve dúvidas em desapropriar todas as florestas da Birmânia, reconhecendo o interesse público como superior ao particular.

Brandis, ao invés de perseguir os fazendeiros de taungya (roça), agiu de maneira oposta: organizou viveiros de mudas de pau-teca e chamou os nativos para que plantassem fileiras intercalares delas em seus roçados, mediante pequeno pagamento. Ao abandonar o roçado para abrir outro, permanecia o nativo como proprietário daquelas mudas de pauteca qua havia plantado; mas só podia cortá-las decorridos vinte anos. Findo esse prazo, o próprio governo da colônia comprava a madeira ao nativo, pelo preço corrente no mercado.

Este sistema, denominado taungya-forestry system, combinava duas atividades aparentemente antagônicas e tornou a floresta da região mais rica em pau-teca do que o era antes de ser povoada. Tamanho foi o sucesso por ele alcançado que Brandis foi encarregado pelo governo inglês de contratar outros silvicultores na Alemanha e fundar a primeira escola superior de silvicultura na Inglaterra. Transferido para Calcutá em 1864, fundou o Serviço Florestal Indiano. O taungya-forestry system ficou amplamente divulgado na Índia, onde, além do pau-teca, passaram a cultivar também outra árvore, chamada "saal" ou "sal" (Shorea robusta), pelo mesmo sistema. Este foi paulatinamente difundido, primeiro em Java, depois nos trópicos úmidos da África Oriental e Ocidental.

Em terras africanas, novas árvores foram introduzidas no taungya-forestry system, como Juniperus procera, Pinus americanos e o cipreste mexicano. No Brasil, há informação apenas de uma experiência-piloto recente deste sistema ${ }^{7}$, no distrito de Belterra, em Santarém (Pará) com o cultivo de duas espécies amazônicas: o freijó (Cordia goeldiana) e a fava-amarga (Leguminosae), mas ainda sem resultados definitivos. Na Estação Experimental de Silvicultura de Curuá-Una foi selecionada uma espécie de madeira nobre nativa, a quaruba (Vochysia maximal, que se torna árvore adulta aos quinze anos, sendo, portanto, apropriada economicamente para ser introduzida nos referidos sistemas agrossilviculturais.

A descolonização dos países tropicais do VeIho Continente (IIndia, Birmânia, Zaire, Indonésia, etc.) foi aproveitada pelas grandes madeireiras para negociarem com os novos governos, inexperientes, endividados ou comprometidos, que permitiram o saque às suas florestas equatoriais. M.K. Ranjitsinh (1979), da Organização das Nações Unidas para Alimentação e Agricultura-FAO, denunciou que, anualmente, são derrubadas 5.000 .000 de hectares dessas florestas na Ásia.

No Brasil, a exploração da hiléia amazônica, 
após o surto da borracha, obedeceu esquematicamente a três fases.

\section{Primeira fase: colonização}

por pequenos proprietários, ao longo de eixos rodoviários recém-construídos (1971-73)

Para realizar a abertura e a colonização ao longo da Transamazônica houve uma concentração de esforços e de verbas federais. Diferentes segmentos da estrada projetada foram entregues a firmas de construção rodoviária, e os trechos que a elas não interessaram foram construídos por Batalhões de Engenharia e Construções - BEC's, do Exército.

Os objetivos declarados do projeto eram: dar acesso à terra a cem mil famílias de agricultores; absorver os excedentes demográficos do Nordeste, a fim de aliviar-Ihe o problema agrário; inaugurar em terras longínquas da Amazônia uma economia rural com base na agricultura e na pecuária.

Os resultados efetivos desse plano foram os seguintes: mal ou bem, no trecho da Transamazônica entre Marabá e Itaituba, único nessa rodovia onde se fez colonização oficial, ficaram assentadas cerca de dez mil famílias de colonos pobres; portanto, apenas $10 \%$ do objetivo colimado foram realmente atingidos, sendo, portanto, insuficiente e não resolveu a crise agrária do Nordeste. Não resolveu nem resolverá, porque o problema agrário nordestino é estrutural e tem que ser resolvido naquela mesma região.

Em contrapartida, a colonização ao longo da Transamazônica não causou a devastação prevista por muitos críticos do projeto, visto que os colonos ali colocados eram geralmente pobres; derrubam a mata com machado e foice, empregando quase sempre mão-de-obra exclusivamente familiar. Excetuando-se o Acre, onde o Instituto Nacional de Colonização e Reforma Agrária-INCRA não teve quase nenhuma atuação, a construção da Rodovia Transamazônica não acarretou devastações alarmantes.

Por outra parte, a BR-364, ligando Porto Velho a Cuiabá recebeu, até meados da década de 70 , mais de vinte mil famílias de migrantes espontâneos, vindos, sobretudo, do Paraná. O afluxo desses migrantes superou, em muito, a capacidade do INCRA para assentá-los como parceleiros. Instalaram-se, por isso, como posseiros, nas proximidades dos projetos de colonização, tendo mesmo, em alguns casos, entrado em choque com indígenas, por causa da invasão de suas terras. Alí, o desmatamento se tornou muito sério.

$\mathrm{Na}$ realidade, quem prosperou espetacular- mente foram as firmas de construção rodoviária. Os resultados gerais desses projetos ficaram aquém das expectativas, por duas razões principais: incapacidade para atender ao afluxo de migrantes (BR-364); falta de assistência aos colonos e precária manutenção das estradas, depois de 1973.

\section{Segunda fase: Grandes projetos agropecuários (1974-78)}

A partir de 1974, mudou radicalmente a política de ocupação da Amazônia. Não se financiariam mais minifúndios que, segundo a diretriz do novo governo, esgotavam o solo, aceleravam a erosão e não aumentavam significativamente a produção agrícola, mormente de produtos de exportação. Desde então, o governo federal passou a financiar, através da Superintendência de Desenvolvimento da Amazônia-Sudam, empresas rurais, que aplicariam técnicas mais avançadas, iriam gerar cerca de trinta mil empregos e forneceriam divisas ao país. Planejavase formar na Amazônia um rebanho de dois milhões de bovinos, tendo-se em mira torná-la uma região exportadora de carne.

Uma faixa periférica, no sul e sudeste da hiléia amazônica, em forma de crescente - o Crescente Pastoril, como foi apelidado, na Sudam - . estendendo-se das proximidades de Cuiabá até ó mar, na divisa entre o Maranhão e o Pará, foi a região escolhida para receber maior quantidade de financiamentos e incentivos fiscais, destinados à implantação de tais projetos. Os financiamentos da Sudam eram pagos em três quotas: a primeira para a derrubada e queimada; a segunda para a formação das pastagens, construção de cercas e demais benfeitorias, e a terceira para a formação do plantel. Havia, por isso, pressa, da parte dos empresários, em vencer, quanto antes, cada uma das duas primeiras etapas. Como a área era muito despovoada, organizouse um verdadeiro tráfico de mão-de-obra.

Em resumo: os grandes projetos agropecuários nem sequer tornaram a Amazônia autosuficiente em Carne bovina; mas favoreceu a especulação imobiliária por grandes empresas, muitas delas multinacionais, agravou severamente o problema agrário e a violência na região e provocou uma devastação em larga escala, nas matas do leste e sudeste amazônicos, com graves desequilíbrios ecológicos.

As técnicas de desmatamento têm-se intensificado com grande rapidez. Até 1970, usavam-se apenas o machado e a foice; com esses instrumentos, seis a oito homens levam cerca de uma semana para derrubar 1 hectare. Com moto-serra, empregada a partir de 1971, um homem derruba 1 hectare em dois dias. Com o correntão, usado no desmatamen- 
to de florestas secundárias ou cerradões, por empresas especializadas, cinco a seis homens derrubam 40 a 50 hectares, em um só dia. Esta técnica é aplicada com uma corrente de ferro, de 100 metros de comprimento, pesando 11 toneladas, puxada em suas extremidades por dois tratores pesados, de modo a abrir um vasto corredor pela mata a dentro. Jogando desfolhante sobre a floresta, com um avião agrícola, seu piloto devasta cerca de 100 hectares, em meio dia de trabalho. Várias marcas de desfolhantes podem ser encontradas à venda nos principais centros da Amazônia, como tordon, tribudon, tormona, planudon AR-2, embora condenados pela Secretaria Especial do Meio Ambiente - SEMA. No Acre, ımensas áreas foram desmatadas com o auxílio de desfolhante, não só com o fito de matar as árvores, mas também para afugentar posseiros, seringueiros e índios, que se recusavam a abandonar seus locais de moradia e trabalho. Nessa época, havia recentemente terminado a Guerra do Vietnã, e sobrara grande quantidade de um desfolhante especialmente tóxico, conhecido pelo nome de agente laranja. Ele foi contrabandeado para Manaus, tendo sido provavelmente empregado em larga escala no Acre, resultando que este Estado ficou com muito pasto e pouco gado; até hoje importa gado vivo da Bolívia para o abate. Além disso, contingentes numerosos de sua população rural migraram para os seringais bolivianos, causando certa apreensão às autoridades do país vizinho. Outra parte desses contingentes, talvez maior, migrou para os centros urbanos regionais, fazendo crescer assustadoramente a população marginal das cidades.

No final da década de 70, o Instituto de Pesquisas Espaciais - INPE, analisando imagens do satélite LANDSAT colhidas sobre a Amazônia brasileira em 1973 e 1978, anunciou que 7.700 .000 hectares da nossa hiléia tinham sido devastados, o que equivaleria a 2,96\% da sua superfície. Acrescentou, porém, que a taxa de incremento no referido qüinqüênio fora de $169 \%$ !

Um estudo crítico dos dados fornecidos pelo INPE, efetuado pelo écologo Ph.Fearnside, comprovou que os mesmos eram incompletos e, portanto, inferiores à realidade. Contudo, extrapolando os próprios dados subestimados, calculou, por meio de computador, a tendência ao desaparecimento total da floresta, em cada unidade amazônica da Federação brasileira lo citado autor chama a atenção para o fato de que o cálculo não equivale a uma previsão, mas revela uma tendência). As datas do desaparecimento final seriam as seguintes: Acre em 1.995; Amapá em 2.159; Amazonas em 2.003; Goiás em 1.988; Maranhão em 1.990; Mato Grosso em 1.989; Rondônia em 1.988; Roraima em 2.002 e Pará em 1.991.

\section{Terceira fase: projetos madeireiros}

Já existem, há muito tempo, grandes empresas madeireiras multinacionais extraindo essências nobres na Amazônia brasileira, como: a Georgia Pacific (norte-americana), a Toyomenka (japonesa) e a Brumasa (holandesa).

Um projeto de lei de zoneamento da Amazônia para fins de utilização aguarda oportunidade para ser aprovado pelo Congresso Nacional. De acordo com tal projeto, 50 milhões de hectares - área equivalente à do Estado da Bahia - serão destinados a florestas nacionais, sujeitas à exploração madeireira racional e auto-sustentada por grandes companhias, sob contrato com o governo brasileiro. Essa exploração intensiva, proposta pela Sudam desde 1972, pretende atender à crescente demanda de madeiras tropicais nos grandes mercados mundiais, premidos pela irremediável deplecção das florestas dos trópicos asiáticos e africanos.

Acontece que, até hoje, não se formulou em país algum, uma técnica para exploração intensiva e racional das matas heterogêneas dos trópicos. A extração seletiva das essências nobres dispersas nessas matas abre clareiras com a queda das árvores e exige a abertura de numerosos caminhos carroçáveis para a penetração de guindastes e tratores, os quais compactam e degradam os solos. Esses espaços são depois tomados por plantas heliófilas, de crescimento rápido, sem valor comercial.

Por outro lado, os valiosos e pacientes experimentos realizados pela Estação Experimental de Curuá-Una (Convênio FAO/Sudam) e pelo INPA lem Manaus) têm fornecido dados iniciais que poderão orientar o manejo silvicultural de algumas essências florestais (talvez menos de dez), porém nunca a reposição de mais de 250 espécies de árvores, em superfícies contínuas de dezenas de milhares de quilômetros quadrados! Ademais, não foram até hoje organizados na Amazônia grandes viveiros para reposição das espécies vegetais bem-conhecidas.

Sob tais condições, a Floresta Amazônica será saqueada da mesma forma e pelas mesmas empresas que as dos trópicos africanos e asiáticos.

Nas vastas áreas florestais da Amazônia submetidas a esse tipo de exploração serão desencadeados os seguintes processos de degradação ambiental: erosão acelerada, lixiviação ${ }^{8}$ e eluviação ${ }^{9}$ dos solos, destruição da vida microbiana dos mesmos, aumento da carga sólida e do assoreamento dos rios, alteração do clima local e regional (com aumento da amplitude térmica diária, concentração e diminuição das chuvas), alteração dos regimes fluviais, extinção de número incalculável de espécies vegetais e animais. 
Pior ainda que o desastre ecológico serão as conseqüências econômico-sociais que restarão para os habitantes da Amazônia, especialmente aos das classes pobres.

\section{Propostas para um futuro melhor}

Como se vê, toda a política de valorização e desenvolvimento da Amazônia brasileira, desde a nossa independência, foi concebida e aplicada em função de interesses estranhos à região e ao próprio Brasil.

É indispensável mudar radicalmente, quanto antes, essa orientação; como, porém, tão brusca mudança só seria possível em conseqüência de outra mudança na estrutura econômico-social de nosso país, rápidas alterações poderiam ser desde já introduzidas, de modo a refrear poderosamente o ritmo das devastações.

A primeira mudança proposta seria semelhante à do governo imperial inglês na Índia: declarar a Floresta Amazônica propriedade dos estados onde ela está localizada, sujeita a uma legislação normativa e fiscalização do governo federal.

Um acordo com os países exportadores de madeiras tropicais, atuais e potenciais, semelhante à Organização dos Países Exportadores de Petróleo - OPEP, elevaria os preços no mercado mundial. Ao mesmo tempo, o Brasil criaria uma legislação permitindo somente a exportação de madeiras nobres beneficiadas ou em artefatos e, ademais, apenas depois de satisfeitas as demandas anuais do mercado interno, a preços ao alcance dos consumidores.

As rendas obtidas com a economia madeireira nacional reestruturada seriam aplicadas, em sua maior parte, na preservação de nossas florestas e nos experimentos com seu manejo agrossilvicultural.

Tal como se procede em relação aos ecossistemas florestais delicados, situados em países desenvolvidos (taigá siberiana, na URSS; floresta de sequóias, nos EUA), a hiléia brasileira deve ser mantida intacta, na quase totalidade de sua área. Somente em pontos dispersos, bem estudados e escolhidos, deve ser utilizada: solos de elição, boas vias de acesso aos mercados, jazidas minerais...

\section{Notas}

1. Floresta de pinheiros, típica das regiões frias.

2. Conforme G. Prance, The Amazon: earth's most dazzling forest. Revista Garden (número especial sobre a Amazônia) v. 6, n. 1, p. 2-10, jan./fev. 1982.

3. Mesozóica ou Secundária: era geológica iniciada há cerca de duzentos milhões de anos, na qual predominaram entre os vertebrados os grandes répteis (dinossauros).

4. BROWN Jr., KEITH S. \& AB'SABER, Aziz Nacib. Ice-age forest refuges and evolution in the neotropics; correlation of paleoclimatological geomorphological and pedological data with modern biological endemism. São Paulo, Instituto de Geografia da USP, 1979. p. 6 (Série Paleoclimas, 5)

5. Transgressão é a inundação de terras, em conseqüência de uma elevação do nivel do mar ou uma subsidência do continente. Recebeu o nome de flandriana a transgressão marinha que sucedeu à última glaciação quaternária.

6. Diz-se que uma formação vegetal atingiu o seu climax quando sua evolução como revestimento está em equilibrio com as condições de clima reinantes no presente, naquela região.

7. Informação verbal do engenheiro agrônomo Wanderbilt Duarte de Barros.

8. Lixiviação é a descida de bases solúveis e húmus do solo, dissolvidos na água de infiltração, até o lençol freático, de onde é levado para os rios.

9. Eluviação é a descida de partículas finas, das frações argila e silte, arrastadas pelas águas de infiltração das chuvas para os horizontes inferiores do perfil do solo, modificando a textura deste.

\section{Bibliografia}

DEFFONTAINDES, Pierre. A floresta a serviço do homem do Brasil. Rio de Janeiro, Conselho Nacional de Geografia, Boletim GeográfiCO, 3 (28): 561-8, 1945.

FEARNSIDE, Philip M. Desmatamento na Amazônia. Brasileira; com que intensidade vem ocorrendo? Manaus, INPA, Acta Amazônica, 12 (3): 579-90.1982.

GALVĀO, Maria C.C. Sistemas agricolas no Congo Belga. Boletim Carioca de Geografia, 9 (1/2): 5-28,1956.

RANJITSINH, M.K. Forest destruction in Asia and the South Pacific. Stockholm, AMBIO, 8 (5): 192-201, 1979.

SALATI, Enéas et alii. Origem e distribuição das chuvas na Amazônia. Interciência, 3: 200-5, 1978.

SIOLI, Harald. Conservação e proteção de fauna e flora. Rio de Janeiro, CNDDA, Amazônia Brasileira em Foco, 14: 83-97, 1981/2. 


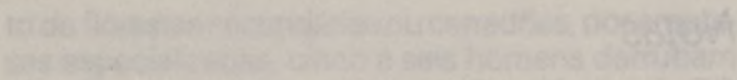

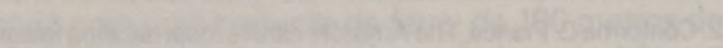

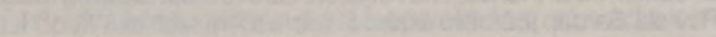

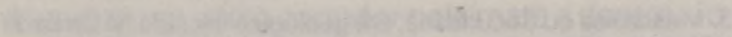

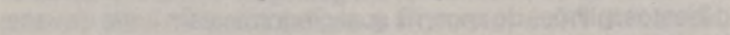

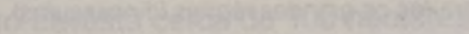

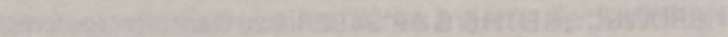

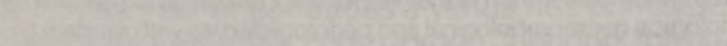

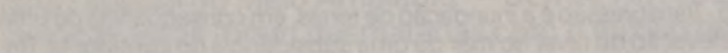

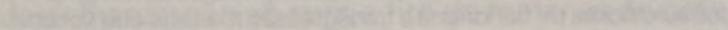

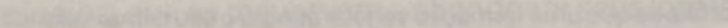
and

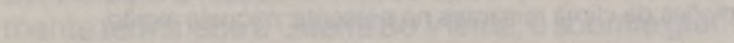

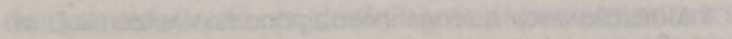

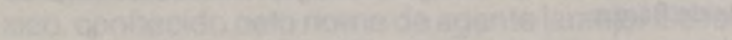

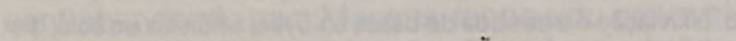

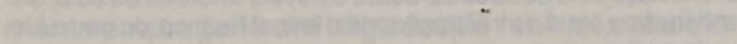

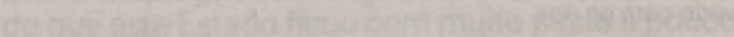

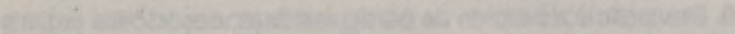

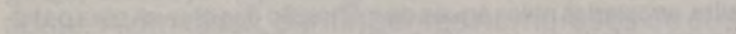

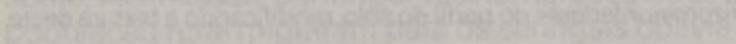

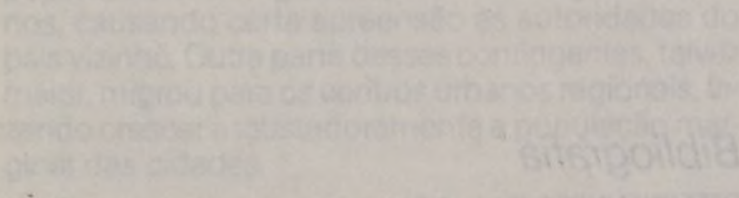

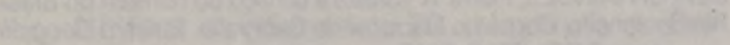

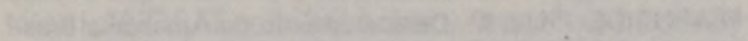

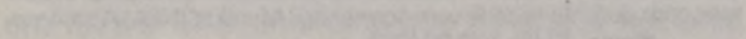

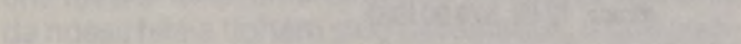

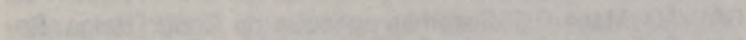

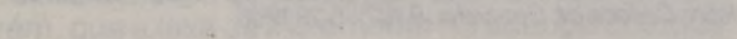

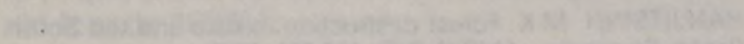

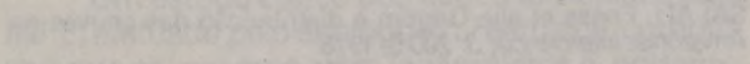

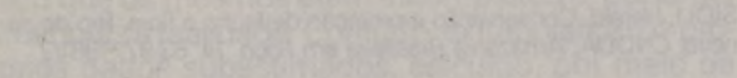

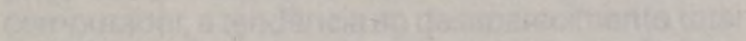

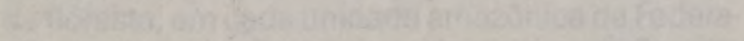

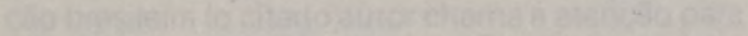

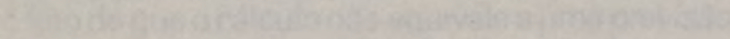

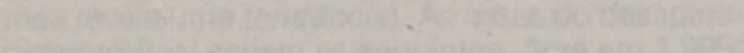

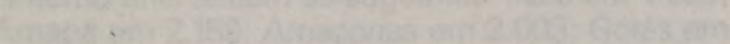

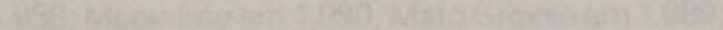

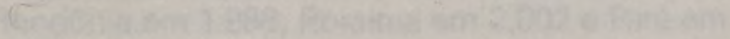

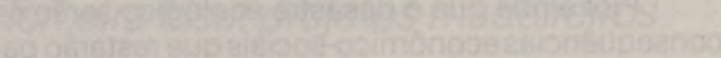

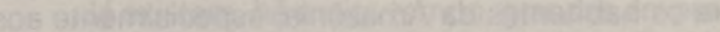

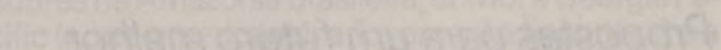

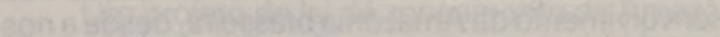

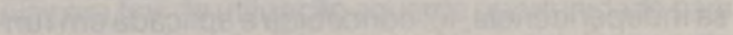

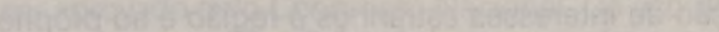

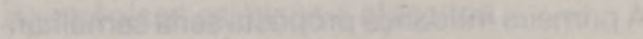

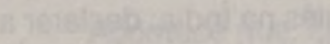

Pang

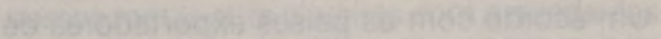

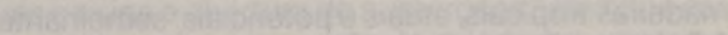

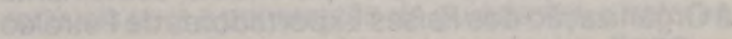

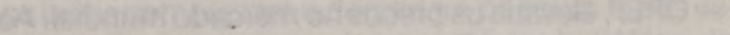

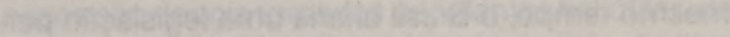

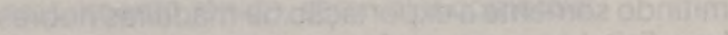

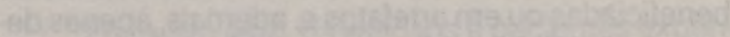

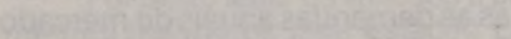

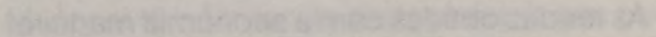

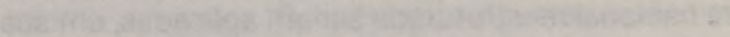

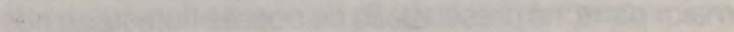

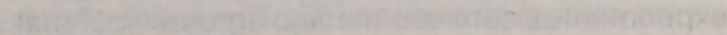

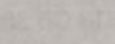

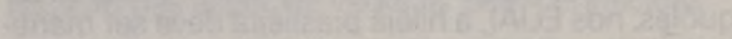

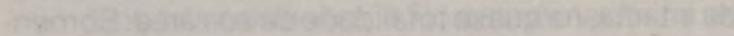

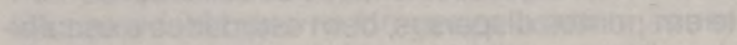

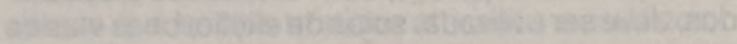

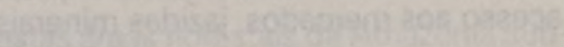

